\title{
Gıda İşletmelerinde Üretim Reçetesinin Denetim Yönünden Ele Alınması ${ }^{*}$
}

\author{
Addressing the Bill of Material in Food Premises in Terms of Audit \\ Serpil Sumer ${ }^{* * 1}$ (iD) Ramazan Yanık ${ }^{2}$ (iD \\ ${ }^{1}$ Department of Finance and Banking, Atatürk University, Erzurum, Turkey \\ ${ }^{2}$ Department of Business, Atatürk University, Erzurum, Turkey
}

\begin{abstract}
Received: 28.06 .2021
Accepted: 28.09.2021

This article was checked by intihal.net

Öz

Küresel rekabet ortamında işletmelerin rekabet avantajı elde etmeleri varlıklarııın devamı için gerekmektedir. Birçok işletme varlı̆̆ını devam ettirmek ve aynı faaliyet kolunda üretim yapan diğer işletmelere karşı rekabet üstünlüğü sağlamak için çeşitli stratejiler geliştirmektedir. Üretim reçetesi kullanımı da işletmelerin rekabet avantajı elde etmeleri için kullandıkları yöntemlerden biridir. Üretim reçetesi işletmelerin maliyetlerini kontrol altında tutarak rekabet güçlerini arttırmasına yardım etmektedir. Bu çalışmanın amacı gıda işletmelerinde kullanılan üretim reçetelerini muhasebe kapsamında üretimde yapılan hileler ve manipülasyonlar yönünden ele alarak incelemektir. Çalışmada iki temel varsayımda bulunulmuştur. Çalışma kapsamında alınan işletmenin gelir tablosu da bu varsayımlar doğrultusunda düzenlenmiştir. Çalışmanın sonunda varsayımların altında yatan olası sebepler sıralanarak çözüm önerisinde bulunulmuştur. Üretim reçetelerinin denetim boyutuna yönelik yapılan bu çalışma literatürdeki boşluğa dikkat çekmesi yönünden son derece önemlidir. Nitekim işletmelerin finansal tabloları mevcut ve potansiyel yatırımcılar için önem arz etmektedir. Üretim reçetelerinin denetimi ile hem işletmeler etkin maliyet kontörlü sağlayabilir hem de finansal tablo kullanıcılarına doğru ve güvenilir bilgiler sunulabilir.
\end{abstract}

Anahtar Kelimeler: Üretim Reçetesi, Hata, Hile

\section{Abstract}

It is necessary for enterprises to gain competitive advantage for the continuation of their existence, in the global competitive environment. Many enterprises develop various strategies to maintain their existence and to gain a competitive advantage against other enterprises producing in the same field of activity. The use of the bill of material is one of the methods used by enterprises to gain competitive advantage. The bill of material helps enterprises to increase their competitiveness by keeping their costs under control. This study aims to examine the bill of material used in food enterprises in terms of cheating and manipulations in production within the scope of accounting. Two basic assumptions were made in the study. The income statement of the enterprise was arranged in line with these assumptions. Possible reasons underlying the assumptions were listed and a solution was suggested. This study on the audit dimension of bill of materials is extremely important in terms of drawing attention to the gap in the literature. Thus, the financial statements of enterprises are important for current and potential investors. With the control of bill of materials, enterprises can both provide effective cost control and provide accurate and reliable information to financial statement users.

Keywords: Bill of Material, Error, Fraud

Sumer, S. \& Yanık, R. (2021). Gıda İşletmelerinde Üretim Reçetesinin Denetim Yönünden Ele Alınması. Journal of Academic Value Studies, 7(3), 368-374. http://dx.doi.org/10.29228/javs.51920

\footnotetext{
* Bu çalışma, 9-11 Haziran 2021 tarihinde Kırgızistan-Bişkek'te düzenlenmiş olan 2. Uluslararası İktisadi ve İdari Bilimler Kongresi'nde özet bildiri olarak sunulmuştur.
}

**E-mail address: serpil.sumer@atauni.edu.tr (Corresponding author) 


\section{Giriş}

İşletmelerin varlıklarını devam ettirerek sürdürülebilirlik sağlaması önemli amaçları arasında yer almaktadır. Birçok işletme varlığını devam ettirmek ve aynı faaliyet kolunda üretim yapan diğer işletmelere karşı rekabet üstünlüğü sağlamak için çeşitli stratejiler geliştirmektedir. Maliyetleri kontrol altında tutması da işletmelerin geliştirdikleri söz konusu stratejilerden biridir. Üretim reçetesi yabancı literatürdeki karşılığı ile "bill of material"; üretim işletmelerinin maliyetlerini kontrol altında tutulmasına yardımcı olan bir sistemdir. İşletmelerde üretim reçetesi bilgisayar teknolojisi yardımı ile gerekli birimlere bilgi verilmesi suretiyle üretim maliyetlerinin kontrol altında tutulmasına yardımcı olmaktadır.

Üretim reçetesi işletmelerin maliyetlerini kontrol altında tutarak rekabet güçlerini arttırmasına yardım etmektedir. Söz konusu rekabet avantajı özelikle üretim işletmelerinin maliyetlerini kontrol altında tutmaları hususunda görülmektedir. İmalat sektöründe üretim reçetesi kontrollü malzeme envanteri, planlı ve optimize edilmiş malzeme tedariki ile envanter yönetimini etkili bir biçimde yapılmasının anahtarıdır (Yang vd. 2016: 1664).

Işletmeler tarafından tutulan ve kamuya açıklanan finansal tablolar işletmeler, yatırımcılar ve kamu için son derece önem arz etmektedir. Karar vericiler ve finansal bilgiyi kullanacaklar işletmelerin yayınladıkları finansal tablolar eşliğinde amaçlarına uygun değerlendirmeler yaparak o yönde hareket etmektedir (Elitaş, 2013:42). Karar vericileri etkilemek için işletmenin finansal durumunun ve faaliyetlerinin manipüle edilerek olduğundan farklı gösterilmesi muhasebe manipülasyonu olarak adlandırılmaktadır (Kıllı ve Evci, 2017; Elitaş, 2013). Yapılan muhasebe manipülasyon ile yatırımcı ve karar vericiler yönlendirilmektedir (Kızıl vd., 2016:2).

Üretim reçetesi, sektörler içerisinde özellikle gıda ve inşaat sektöründe maliyetlerin kontrol altında tutulmasına yönelik kullanılmaktadır. Gıda sektöründe kullanılan üretim reçeteleri "standart reçete" olarak bilinmektedir. Gıda işletmelerinde kullanılan üretim reçetelerinde yani standart reçetelerde yapılacak üründe kullanılan malzemeler, malzemelerin gramları ve fiyatları yer almaktadır. Böylece işletme hem maliyetlerini hem de stoklarını kontrol altında tutarak rakip işletmelere karşı rekabet avantajı elde edebilecektir. Maliyeti kontrol altında tutması üretim reçetelerinin avantajlı yönünü oluştururken, birimler arasında bilgilerin aktarılmasında ortaya çıkacak aksaklıklar, özellikle stoklar ve satın alma birimleri arasında bilgi paylaşımı konusunda aksaklıklar üretim reçetelerinin dezavantajlı yönünü oluşturmaktadır.

Türkiye'deki mevcut literatürde üretim reçetesi ile ilgili yapılan çalışma neredeyse yok denecek kadar azdır. Bu çalışma ile literatürdeki bu boşluğa dikkat çekilmeye çalışımış ve üretim reçetesi kavramı denetim yönünden ele alınmıştır. Mevcut literatürde üretim reçetesi işletmeye sağladığı avantajları yönünden ele alınmıştır. Üretim reçetesinin işletmelere sağladığı tüm avantajlarına rağmen, reçetede var olan bilgilerin değiştirilmesi ya da olduğundan farklı gösterilmesi durumu söz konusu olabilmektedir. Bu çalışmada üretim reçetesinde yapılabilecek hatalı işlemler ele alınmış ve varsayımlar üzerinden gidilerek ortaya çıkabilecek olası durumların altında yatan sebepler araştırılmıştır.

\section{Literatür Taraması}

Rusk'a (1990) göre üretim reçetesi, tek bir parça üretmek için gereken bileşenleri listeleyen basit yapılandırımamış malzeme listesidir. İşletmelerde üretim reçetesi malzeme ve maliyet kontrolü, üretim ve planlama işlevlerinin yerine getirilmesinde yardımcı olmaktadır. Teknoloji ve mühendislik alanında yaşanan gelişmelerle birlikte üretim reçetesinin uygulanabilirliğinde kolaylık sağlamıştır.

Literatürde üretim reçetesine yönelik yapılan çalışmalar genellikle, işletmelerin üretim süreçlerine yardımcı olmasında geliştirilen bir program yardımıyla kullanılması yönünde yapılmıştır. Yapılan çalışmalar incelendiğinde genellikle üretim reçetesinin programlar yardımı ile uygulanabilirliğine yönelik olarak yapılan deneysel çalışmalardan oluşmaktadır.

Inş̧aat, imalat ve gıda sektörü başta olmak üzere üretim işletmeleri üretim maliyetlerini kontrol altında tutmak için çeşitli programlar geliştirmişlerdir. İnşaat ve imalat sektöründe faaliyetlerini üretim reçetesine göre yürüten işletmelerin ele alındığı çalışmalarda işletmelerin başarılı oldukları ifade edilmiştir (Solechal ve Yulia, 2020; Akinradewo vd., 2021; Cinellli vd. 2020; Yang vd. 2016; Sari vd. 2018). Faaliyetlerini üretim reçetesini dikkate alarak yürüten işletmelerde ilk önce üretim reçetesinin tasarımı yapılmakta daha sonra MySQL, Excel, Extreme Programming (XP)gibi programlar yardımı ile üretim süreci gerçekleşmektedir (Akinradewo vd. 2021; Solechal ve Yulia 2020; Sari vd., 2018). Üretim sürecinde üretim reçetesinin kullanıldığı işletmelerde bilgi yönetimi ve bilgilerin farklı sistemler arasında 
paylaşımı konusunda zorluklar yaşanmaktadır. Bilgilerin doğru bir şekilde iletilmesi için işletmelerde ek bir sisteme ihtiyaç duyulmuştur (Yang vd. 2016, 1664).

Literatürde yapılan çalışmalarda üretim reçetesi mühendislik yönü ile ele alınmış, üretim reçetelerinin tasarlanması ve çeşitli programlar yardımı ile uygulanışı ele alınmıştır. Yapılan çalışmalarda da (Akinradewo vd. 2021; Cinellli et. al. 2020; Yang vd. 2016) oluşturulan üretim reçetelerinin üretim sürecinde uygulanabilir olduğu sonucu vurgulanmışır. Okutmuş ve Gövce (2015), yiyecek işletmelerinde maliyet kontrolünün karşılaştırmasını yapmak için Alanya'da faaliyet gösteren bir işletmenin üretim reçetesini ele alarak incelemişlerdir. Araştırmadan elde edilen bulgulara göre bir yiyecek ürünü (yaş pasta) için kullanılan malzemeler standart reçetelerinde gösterilen miktarlardan fazla kullanıldığını, başka bir yiyecek ürününde (ekler) ise malzemelerin daha az kullanıldığını belirtmişlerdir.

\section{Yöntem ve Uygulama}

Bu çalışmanın amacı gıda işletmelerinde kullanılan üretim reçetelerinin muhasebe kapsamında üretimde yapılan hileler ve manipülasyonlar yönünden ele almaktır. Üretim reçetelerine ait bilgiler işletmenin muhasebe, denetim, planlama gibi farklı departmanlarıyla paylaşılmaktadır. Işletmenin finansal tablolarında yer alan bu bilgilerin doğruluğu karar vericiler açısından son derece önemlidir. Bu çalışma ile üretim reçetelerinde yer alan bilgiler ile işletmenin finansal tablolarında yer alan bilgiler karşılaştııılmaya çalışımış ve departmanalar arası bilgi paylaşımı sırasında yaşanabilecek olası hata ve hileler varsayımlarla ele alınmaya çalışılmıştır.

Bu çalışmada üretim reçetesi kullanarak üretim yapan gıda işletmelerinde denetim yönünden ortaya çıkabilecek durumlar varsayımlarda bulunularak ele alınmıştır. Çalışmada örnek işletme olarak hazır gıda ürün reçetesini kullanmak için Ülker Bisküvi Sanayi A.Ş’ nin çikolata ürünü seçilmiştir. Paketli gıda ürünlerinin ambalajlarında o ürünün içeriğine yönelik olarak üretim reçetesi bulunmaktadır. Bu çalışmada örnek olarak ele alınan Ülker çikolatanın (80 gram) üretim reçetesinde yer alan bilgiler aşağıdaki gibidir:

Kakao Kitlesi, Şeker, Kakao yağı, Kakao tozu, Peyniraltı suyu tozu, Sadeyağ, Emülgatörler (Soya Lesitini, Sorbitan Tristearat, Poligliserol Polirisinoleat), Aroma verici. Pakette belirtildiği üzere şeker 30 gr, toplam yağ miktarı 27,9 gr, kakao 20,3 gr. Pakette yer alan gramaja ilişkin maliyetler işletmenin faaliyet raporuna yansımaktadır.

Çalışma kapsamında iki varsayımda bulunulmuştur.

Varsayım 1: Çalışmamızda konu aldığımız ürünün gramajlarının olması gerekenden \%20 daha fazla gösterildiğini varsayalım. Bu durumda ürünün gramajı 80 gr yerine yaklaşık olarak 66,7 gram olacaktır.

Varsayım 2: Yine ürünün gramajlarının olması gerekenden \%20 daha az gösterildiğini varsayalım. Bu durumda ürünün gramajı 80 gr yerine yaklaşık olarak 96 gram olacaktır.

Tablo 1. Ülker Bisküvi Sanayi A.Ş.'nin 2020 Yılı Çikolata Satış Hacmi ve Net Satışları

\begin{tabular}{|l|c|}
\hline Yıl & 2020 \\
\hline Stoklar & 219.000 \\
\hline Satış Hasılatı & $4.694 .000 \mathrm{TL}$ \\
\hline
\end{tabular}

Ülker'in 2020 faaliyet raporuna göre; işletme 2020 yılında 219.000 tonluk bir satış gerçekleşmiş ve bu satıştan da 4.694.000 TL'lik hasılat elde edilmiştir.

Varsayım 1 dikkate alındığında;

İşletmenin ürünün gramajını olması gerekenden \%20 daha fazla göstermektedir. İşletmenin 80 gramlık ürün yerine yaklaşık olarak 66,7 gramlık ürün üretmesi işletmenin daha az stok kullanmasını gerektirecektir. Ancak varsayımımıza göre işletme üretim reçetesinde daha fazla malzeme kullandığıı ileri sürmektedir. Bu durumda işletme 219.000 ton yerine 182.591 ton stok kullanmış olması gerekmektedir. Bu durumda işletmenin satış hasılatının 4.694.000 TL yerine 3.913.617 TL olması gerekirdi. Bu varsayım altında işletmenin hasılatında (4.694.000-3.913.617) 780.383 TL'lik bir fark meydana gelecektir. İşletmenin hasılatı değişeceği için faaliyet raporunda bulunan gelir tablosunda yer alan bilgiler de değişecektir. Varsayım 1 olasııı̆ı göz önünde bulundurulduğunda hasılatta meydana gelen farkın işletmenin gelir tablosunda yol açacağı değişiklikler Tablo 2'de sunulmuştur. 
Tablo 2. Ülker Bisküvi Sanayi A.Ş. 2020 Kapsamlı Gelir Tablosu (Bin TL)

\begin{tabular}{|c|c|c|}
\hline & $\begin{array}{c}2020 \text { Faaliyet } \\
\text { Raporunda } \\
\text { Gösterilen }\end{array}$ & $\begin{array}{c}\text { Varsayım } 1 \\
\text { Durumunda } \\
\text { Olması } \\
\text { Gereken }\end{array}$ \\
\hline Hasılat & 9.400 .861 & 8.620 .478 \\
\hline Satışların Maliyeti & $(6.757 .398)$ & $(6.757 .398)$ \\
\hline Brüt Kâr & 2.643 .463 & 1.863 .080 \\
\hline Genel Yönetim Giderleri & $(263.248)$ & $(263.248)$ \\
\hline Pazarlama Giderleri & (921.325) & $(921.325)$ \\
\hline Araştırma ve Geliştirme Giderleri & $(24.209)$ & $(24.209)$ \\
\hline Esas Faaliyetlerden Diğer Gelirler & 229.896 & 229.896 \\
\hline Esas Faaliyetlerden Diğer Giderler & $(171.839)$ & $(171.839)$ \\
\hline Esas Faaliyet Kârı & 1.492 .738 & 712.355 \\
\hline Yatırım Faaliyetlerinden Gelirler & 2.503 .149 & 2.503 .149 \\
\hline Yatırım Faaliyetlerinden Giderler & (683.929) & (683.929) \\
\hline Finansman Gelirleri Ve Giderleri Öncesi Faaliyet Kârı & 3.311 .958 & 2.531 .575 \\
\hline Finansman Gelirleri & 555.442 & 555.442 \\
\hline Finansman Giderleri & $(2.372 .753)$ & $(2.372 .753)$ \\
\hline Faaliyetler Vergi Öncesi Kârı & 1.494 .647 & 714.264 \\
\hline Vergi Gideri & (291.062) & $(291.062)$ \\
\hline Dönem Vergi Gideri & (349.929) & (349.929) \\
\hline Ertelenmiş Vergi Geliri/(Gideri) & 58.867 & 58.867 \\
\hline Dönem Kârı & 1.203 .585 & 423.202 \\
\hline
\end{tabular}

Tablo 2'de sunulduğu gibi varsayım 1 olasılığı altında yapılan üretimde işletmenin başta hasılat kalemi olmak üzere gelir tablosunda yer alan brüt kâr, esas faaliyet kârı, finansman gelirleri ve giderleri öncesi faaliyet kârı, faaliyetler vergi öncesi kârı ve dönem kârında değişiklikler meydana gelmiştir. İşletmenin dönem kârı 1.203.585 TL iken varsayım 1 durumunda 423.202 TL olmuştur. İşletme varsayım 1'e göre gelir tablosunda dönem kârını (1.203.585-423.202) 780.383 TL daha fazla göstermiştir.

Varsayım 2 dikkate alındığında;

Işletmenin ürünün gramajını olması gerekenden \%20 daha az göstermektedir. İşletmenin 96 gramlık ürünü üretim reçetesinde 80 gr gösterdiği varsayılmaktadır. Bu durumda işletme 219.000 ton yerine 262.800 ton stok kullanmış olması gerekmektedir. Bu durumda işletmenin satış hasılatının 4.694.000 TL yerine 5.632.800 TL olması gerekirdi. Bu varsayım altında işletmenin hasılatında 938.800 TL'lik bir fark meydana gelecektir. İşletmenin hasılatı değişeceği için faaliyet raporunda yer alan gelir tablosunda yer alan bilgiler de değişecektir. Varsayım 2 olasılığı göz önünde bulundurulduğunda hasılatta meydana gelen farkın işletmenin gelir tablosunda yol açacağı değişiklikler Tablo 3'te sunulmuştur. 
Tablo 3. Ülker Bisküvi Sanayi A.Ş. 2020 Kapsamlı Gelir Tablosu (Bin TL)

\begin{tabular}{|l|c|c|}
\hline & $\begin{array}{c}2020 \text { Faaliyet } \\
\text { Raporunda } \\
\text { Gösterilen }\end{array}$ & $\begin{array}{c}\text { Varsayım 2 } \\
\text { Durumunda } \\
\text { Olması } \\
\text { Gereken }\end{array}$ \\
\hline Hasılat & 9.400 .861 & 10.339 .661 \\
\hline Satışların Maliyeti & $(6.757 .398)$ & $(6.757 .398)$ \\
\hline Brüt Kâr & 2.643 .463 & 3.582 .263 \\
\hline Genel Yönetim Giderleri & $(263.248)$ & $(263.248)$ \\
\hline Pazarlama Giderleri & $(921.325)$ & $(921.325)$ \\
\hline Araştırma ve Geliştirme Giderleri & $(24.209)$ & $(24.209)$ \\
\hline Esas Faaliyetlerden Diğer Gelirler & 229.896 & 229.896 \\
\hline Esas Faaliyetlerden Diğer Giderler & $(171.839)$ & $(171.839)$ \\
\hline Esas Faaliyet Kârı & 1.492 .738 & 2.431 .538 \\
\hline Yatırım Faaliyetlerinden Gelirler & 2.503 .149 & 2.503 .149 \\
\hline Yatırım Faaliyetlerinden Giderler & $(683.929)$ & $(683.929)$ \\
\hline Finansman Gelirleri Ve Giderleri Öncesi Faaliyet Kârı & 3.311 .958 & 4.250 .758 \\
\hline Finansman Gelirleri & 555.442 & 555.442 \\
\hline Finansman Giderleri & $(2.372 .753)$ & $(2.372 .753)$ \\
\hline Faaliyetler Vergi Öncesi Kârı & 1.494 .647 & 2.433 .447 \\
\hline Vergi Gideri & $\mathbf{2 9 1 . 0 6 2 )}$ & $\mathbf{( 2 9 1 . 0 6 2 )}$ \\
\hline Dönem Vergi Gideri & 1.203 .585 & 2.142 .385 \\
\hline Ertelenmiş Vergi Geliri/(Gideri) & $0.929)$ & $(349.929)$ \\
\hline Dönem Kârı & 58.867 \\
\hline
\end{tabular}

Tablo 2'de sunulduğu gibi varsayım 2 olasılığı altında yapılan üretimde işletmenin başta hasılat kalemi olmak üzere gelir tablosunda yer alan brüt kâr, esas faaliyet kârı, finansman gelirleri ve giderleri öncesi faaliyet kârı, faaliyetler vergi öncesi kârı ve dönem kârında değişiklikler meydana gelmiştir. İşletmenin dönem kârı 1.203.585 TL iken varsayım 2 durumunda 2.142.385 TL olmuştur. İşletme varsayım 2’ye göre gelir tablosunda dönem kârını daha az göstermiştir.

İşletmelerin ürünlerini üretim reçetelerinde yer alan bilgilerini daha fazla ve daha az göstermesinin altında çeşitli sebepler yatmaktadır. İşletmenin gıda ürününü olması gerekenden daha fazla ve daha az göstermesinin altında yatan olası sebepleri şu şekilde sıralayabiliriz:

- Iş̧letme ürünün gramajını olması gerekenden daha fazla göstererek stoklarını arttırmak isteyebilir. İşletmenin stokları artınca işletmenin aktifi (varlıkları) büyüyecek ve bu durum kârlılı̆ın artışı olarak algılanabilecektir.

- Bir başka olasılık ise; işletme var olan zararını mevcut ve potansiyel yatırımcılardan gizlemek için stoklarını daha fazla gösterilebilir.

- İşletme ürünün gramajını olması gerekenden daha az göstererek kayıt dışı üretim ve satış yapıyor olabilir.

- Bu durumun bir diğer sebebi, işletmenin üretmesi gereken standart ve kalitede üretim yapmıyor olması olabilir. İşletme hatalı ya da bozuk üretim yapıyor olabilir. 
- Ayrıca ürünün üretim reçetesinde olması gerekenden daha az gösterilmesinin altında yatan bir diğer neden de malzemelerin çalınıyor olması ihtimalidir.

\section{Sonuç}

Küresel rekabet ortamda işletmelerin rekabet avantajı elde etmeleri varlıklarının devamı için son derece önemlidir. Üretim reçetesi kullanan işletmeler maliyetleri kontrol altında tutarak aynı faaliyet kolundaki diğer işletmelere karşı rekabet avantajı elde etmeye çalışmaktadır. Üretim reçetelerinin etkin şekilde kullanılması işletmelere avantaj sağlayacaktır. Üretim reçetelerinin denetiminin yapılmaması üretim reçetelerinin kullanım amaçlarının dışına çıkmasına yol açmakta ve işletme için avantaj olmaktan çıkmaktadır.

Tüm sıralanan olasılıklar göz önünde bulundurulduğunda her ne kadar maliyet kontrolü için üretim reçeteleri işletmeler tarafından tercih ediliyor olsa da üretim reçetelerinin denetimi inmal edilmemelidir. Küresel rekabet ortamında gıda işletmeleri üretim reçetesi kullanarak maliyet kontrolü ve rekabet avantajı sağlayabilir. İşletmeler bu amaca üretim reçetelerinin denetimi ile elde edecekleri etkin maliyet kontrolü yardımı ile ulaşabilirler. Reçetelerin denetimi hem olası hata, hile durumunu ortadan kaldıracak hem de etkin maliyet kontrolü sayesinde işletmenin kârııı̆ı artacaktır.

Ortaya çıkacak olası durumları önlemek için;

- Gıda işletmelerinde kontrolün sağlanabilmesi için özellikle satın alma ve stok birimleri arasındaki kontrol ve denetimin yapılması ile üretim reçetelerinin kontrolü sağlanabilir,

- Gıda işletmelerinde tüm ürün reçetelerine belli bir mesai ayrılarak tek tek gözden geçirilip kontroller yapılabilir. Ancak bu yöntem hem maliyetli hem de zaman alıcı olduğu için "Örnekleme Denetim" yöntemi yardımı ile ana kütleyi oluşturan az sayıda birimin incelenmesiyle ana kütleye ilişkin bir görüş oluşturulabilir.

- Üretim reçetesinde yer alan bilgilerin doğruluğunu teyit ederken denetim tekniklerinden özellikle; karşılaştırma ve aritmetik inceleme, yeniden hesaplama, envanter sayım ve inceleme teknikleri ile işletmelerin üretim reçetelerinin denetimi sağlanabilir.

- Özellikle hazır gıda ürünlerinin gramajlarına yönelik tüketici şikâyetleri dikkate alınmalı ve cezai yaptırım uygulanmalıdır,

- Var olan cezai yaptırımlar ise gözden geçirilmelidir.

Bu çalışmada gıda işletmelerinde kullanılan üretim reçetelerinden yapılabilecek hata hile durumu varsayımlar doğrultusunda ele alınarak incelenmeye çalışılmıştır. Bu çalışmada iki varsayım üzerinde durulmuş ve bu durumları ortaya çıkarabilecek olası sebepler üzerinde düşünülmüştür. Gelecek çalışmalarda üretim reçetelerinde yapılabilecek hata hile durumları farklı varsayımlar üzerinden ele alınabilir.

\section{Kaynakça}

Akinradewo, O. I., Awodele, O. A., \& Akinradewo, O. F. (2021). Bill of material and labour template for construction Information management. Journal of Engineering, Project, and Production Management, 11(1), 52-60.

Cinelli, M., Ferraro, G., Iovanella, A., Lucci, G., \& Schiraldi, M. M. (2020). A network perspective for the analysis of bill of material. Procedia CIRP, 88, 19-24.

Elitaş, B. L. (2013). Muhasebe manipülasyonu ve muhasebe bilgi kalitesine etkisi. Muhasebe ve Finansman Dergisi, (58), 41-54.

Kıllı, M., \& Evci, S. (2017). Muhasebe manipülasyonlarının tespitinde kullanılan modeller. Osmaniye Korkut Ata Üniversitesi Iktisadi ve Idari Bilimler Fakültesi Dergisi, 1(1), 68-79.

Kızıl, C., Akman, V., Çelik, I. E., \& Şener, S. (2016) "Yaratıcı muhasebe yöntemleri ve finansal bilgilerin manipülasyonu: profesyonel muhasebe meslek mensupları üzerinde örnek bir uygulama." Beykent Üniversitesi Sosyal Bilimler Dergisi 9.(1) 1-18.

Okutmuş, E., \& Gövce, G. (2015). Yiyecek işletmelerinin maliyet kontrolünde standart reçetelerin karşılaştırmalı olarak incelenmesi ve bir uygulama. Niğde Üniversitesi Iktisadi ve Idari Bilimler Fakültesi Dergisi, 8(2), 79-90. 
Rusk, P. S. (1990). The role of the bill of material in manufacturing systems. Engineering Costs and Production Economics, 19(1-3), 205-211.

Sari, B. N., Komarudin, O., Padilah, T. N., \& Nurhusaeni, M. (2018). Bıll of materıal (bom) pada sıstem ınventorı kawasan berıkat untuk pelacakan materıal movement. Ilkom Jurnal IImiah, 10(3), 323-330.

Solecha, K., \& Yulia, E. R. (2020). Rancang bangun sistem informasi pengelolaan sales order dan bill of material Interior dan exterior bangunan menggunakan model waterfall. Jurnal Teknologi Informasi, 6(1), 48-54.

Yang, Z., Zhang, J., Wang, S., Wang, J., \& Huang, X. (2016, August). Building ontology-based bill of material design and knowledge management in power gird. In 2016 12th International Conference on Natural Computation, Fuzzy Systems and Knowledge Discovery (ICNC-FSKD) (pp. 1664-1669). IEEE. 